\title{
Stilbene Aldehyde
}

National Cancer Institute

\section{Source}

National Cancer Institute. Stilbene Aldehyde. NCI Thesaurus. Code C29440.

An organic derivative of the unsaturated hydrocarbon stilbene, an aromatic alkene that is the nucleus of diethylstilbestrol and related compounds. Stilbene aldehyde is used in the chemical synthesis of estrogenic agents as well as for the manufacture of research reagents such as trans-stilbene oxide, a substrate for glutathione S-transferase.

Estrogenic compounds containing the stilbene nucleus are known to be carcinogenic in humans and animals. ( $\mathrm{NCl04)}$ 